\title{
ERRATA
}

\section{Erratum: Long-time relaxation of an ordered magnetic structure [Phys. Solid State 40, 467-470 (March 1998)]}

S. K. Godovikov, Yu. D. Perfil'ev, Yu. F. Popov, and A. I. Firov

Fiz. Tverd. Tela (St. Petersburg) 40, 2239 (December 1998)

[S1063-7834(98)02212-6]

Figure 2 in this article should read as follows:

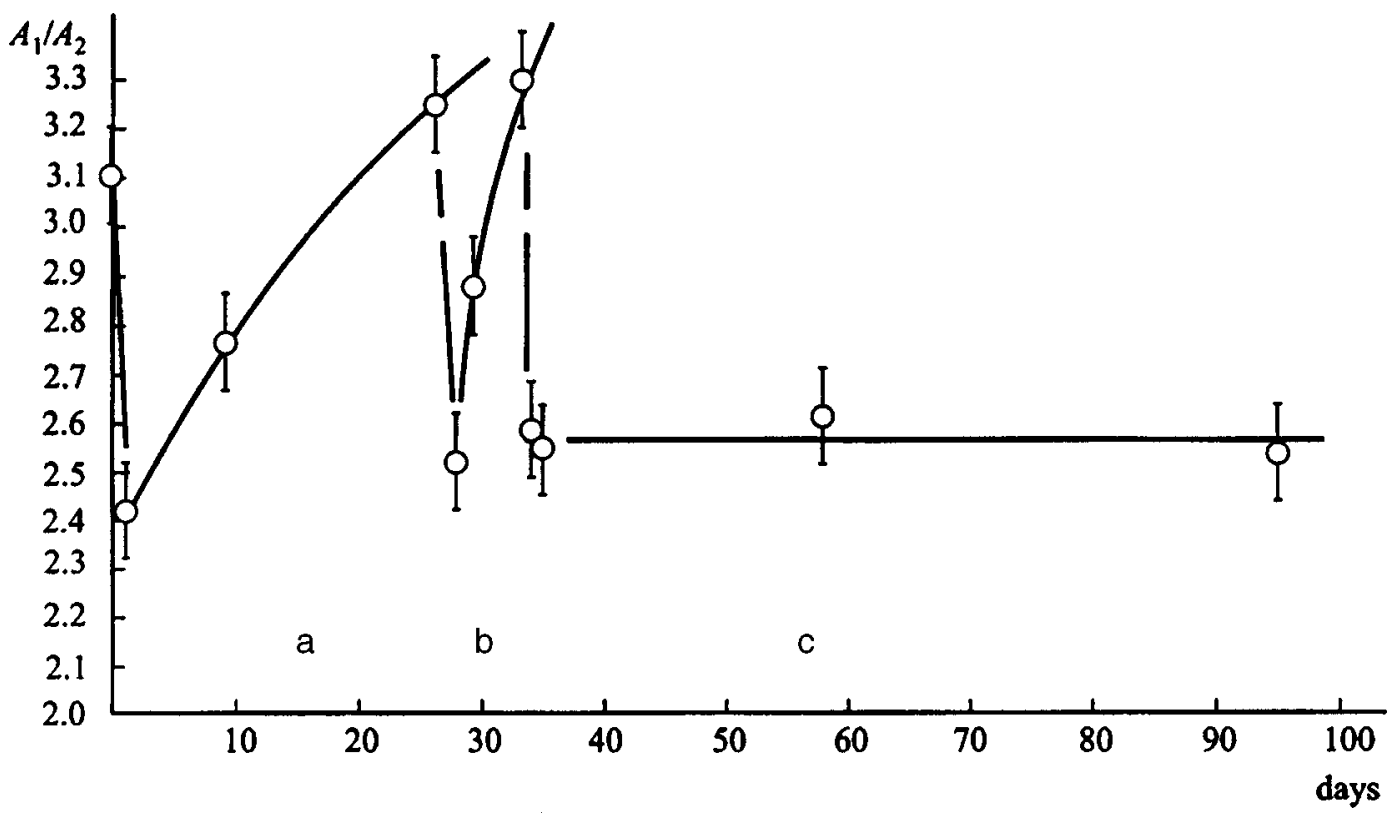

FIG. 2. Long-time relaxation in $\mathrm{Tb}_{0.8} \mathrm{Y}_{0.2} \mathrm{Fe}_{2}$. a-After the application of a $125 \mathrm{kOe}$ field, b-after repeated application of a $125 \mathrm{kOe}$ field, c-after the application of a $150 \mathrm{kOe}$ field. 